\title{
O USO DE INFOGRÁFICOS DE GENÉTICA COMO RECURSO DIDÁTICO NO ENSINO MÉDIO
}

\author{
'Larissa Fernandes
}

2Bruno Duarte Ziroldo

\section{RESUMO}

Infográficos são gêneros de textos multimodais, comumente apresentados no jornalismo em notícias, reportagens ou até em divulgação tecnológica-científica. Por se valer de uma combinação entre linguagens verbal e não verbal, o infográfico é um recurso didático interessante para ser utilizado também no ensinoaprendizagem de jovens do ensino médio. Quando analisamos os conteúdos de genética, observamos nos alunos uma certa dificuldade na compreensão dos conceitos devido a sua complexidade, sendo por esse motivo, o ramo da biologia escolhido como tema para a confecção dos infográficos. Este trabalho visa, portanto, criar e disponibilizar ao menos dez infográficos que contemplem diferentes áreas da genética para educadores e educandos do ensino médio e/ou prévestibulandos da comunidade escolar da cidade de Londrina e região. Aproveitando das facilidades decorrentes da evolução digital, serão criados canais de divulgação por meio de redes sociais e outras plataformas que permitirão a divulgação dos infográficos a outras comunidades mais distantes geograficamente, maximizando o compartilhamento de toda informação gerada. Por integrar de forma proporcional as modalidades de informação e imagem, esperamos com esse trabalho contribuir de maneira efetiva tanto com os professores, na transmissão de conceitos genéticos e de suas peculiaridades de forma mais ilustrativa, quanto com os educandos, na assimilação de conteúdos mais densos, de uma forma mais interessante. Acreditamos também que este artigo é capaz de contribuir com futuras pesquisas na área da infografia e com seus benefícios no processo de ensino-aprendizagem.

Palavras-chave: Infográfico. Ensino-Aprendizagem. Genética.

\section{THE USE OF GENETICS INFOGRAPHICS AS A DIDACTIC RESOURCE IN HIGH SCHOOL}

\footnotetext{
${ }^{1}$ Mestranda em Educação. Programa de Pós-Graduação em Ensino de Ciências Humanas, Sociais e da Natureza (PPGEN) da Universidade Tecnológica Federal do Paraná (UTFPR), Londrina, Paraná, Brasil. Orcid iD: https://orcid.org/0000-0003-3257-6381 E-mail: fernandes.larissa.b@gmail.com

${ }^{2}$ Mestre em Genética. Instituto Federal de Educação, Ciência e Tecnologia do Paraná (IFPR), Londrina, Paraná, Brasil. Orcid https://orcid.org/0000-0002-6672-9262 E-mail: bruno.ziroldo@ifpr.edu.br
} 


\section{ABSTRACT}

Infographics are examples of multimodal texts, commonly used in news, reports or even technological-scientific dissemination. By using a combination of textual and representational languages, infographic is an interesting didactic resource to be used also in the high school students teaching and learning. When we analyze the contents of genetics we observe in the students a certain difficulty in understanding the concepts due to their complexity, being for that reason, the biology area chosen as the theme of the infographics. This work aims at creating and sharing at least ten infographics that contemplate different genetic areas, for educators and high school students and/or pre-students from the school community of the city of Londrina and region. Taking advantage of the facilities promoted on the digital evolution, channels of dissemination will be created through social networks and other platforms that will allow the dissemination of the same infographics to other communities more distant geographically, maximizing the sharing of all the information generated. By integrating the information and image modalities in a proportional way, we hope with this work to effectively contribute with both the teachers in the transmission of genetic concepts and their peculiarities in a more illustrative way, as with the students in the assimilation of more dense contents of a more interesting way. We also believe that this article will be able to collaborate with future research in the area of inphographics and its benefits in the teaching-learning process.

Keywords: Infographic. Teaching-Learning. Genetics.

\section{EL USO DE LA INFOGRAFÍA GENÉTICA COMO RECURSO DIDÁCTICO EN LA ESCUELA SECUNDARIA}

\section{RESUMEN}

Las infografías son géneros de textos multimodales, comúnmente presentes en el periodismo en las noticias, en los reportajes o incluso como divulgación científicotecnológica. Debido a que utiliza una combinación de lenguajes verbales y no verbales, la infografía es un recurso didáctico interesante para ser utilizado también en la enseñanza-aprendizaje de los jóvenes en la escuela secundaria. Cuando analizamos los contenidos de genética, observamos que los estudiantes tienen cierta dificultad en comprender los conceptos debido a la complejidad, y por ello, la parte de la biología elegida como tema para la realización de infografías. Este trabajo tiene como objetivo, por tanto, crear y poner a disposición al menos diez infografías que contemplen diferentes áreas de la genética para educadores y alumnos de bachillerato y/o preuniversitario de la comunidad escolar de la ciudad de Londrina y región. Aprovechando las facilidades derivadas de la evolución digital, se crearán canales de difusión a través de las redes sociales y otras plataformas que permitirán la difusión de infografías a otras comunidades geográficamente más alejadas, maximizando el intercambio de toda la información generada. Al integrar las modalidades de información e imagen de manera proporcional, esperamos con este trabajo contribuir de manera efectiva tanto con los docentes, en la transmisión de conceptos genéticos y sus 
peculiaridades de manera más ilustrativa, como con los estudiantes, en la asimilación de contenidos más densos, de una forma interesante. Creemos que este artículo puede contribuir a futuras investigaciones en el área de la infografía y sus beneficios en el proceso de enseñanza-aprendizaje.

Palabras clave: Infografía. Enseñanza-Aprendizaje. Genética.

\section{INTRODUÇÃO}

O infográfico é um recurso de origem jornalística que possui linguagem narrativa e ilustrativa. Essas linguagens são seus dois pontos essenciais e são utilizadas com o intuito de melhorar a compreensão do conteúdo apresentado para o leitor. No infográfico, não basta ter as informações traduzidas em uma linguagem verbal e não verbal, é preciso fazer uma seleção de informações e estabelecer uma relação com as diferentes representações, já que ele permite a exposição de informações de modo mais abrangente, sendo visto como a linguagem do futuro. O infográfico, também pode ser descrito como, uma linguagem visual, um veículo de comunicação. É possível, por exemplo, percebermos o crescimento do uso de infográficos como uma ferramenta de transmissão de notícias online, isso devido a variadas combinações de mídias que o infográfico apresenta. Por isso, é um recurso didático que pode ser utilizado no ensino-aprendizado de jovens-adolescentes (CAIRO, 2008; CARVELHO; ARAGÃO, 2012; COLLE, 2004; IRIA, 2013; RANIERI, 2008).

O infográfico pode ser tratado como uma criação gráfica que utiliza diversos recursos visuais, como fotografias, tabelas, gráficos, desenhos, dentre outros, unidos a textos curtos para a apresentação de informações jornalísticas de modo mais sucinto e atraente. Esse gênero textual pode explicar histórias ou procedimentos complexos de modo mais sofisticado, pois combina imagens e palavras, sendo que somente as palavras poderiam cansar o leitor ou só as imagens tornariam o conteúdo insuficiente. Com isso, para a construção de um infográfico, são necessárias várias etapas que envolvem um alto grau de multidisciplinaridade, que são elas: a pesquisa do conteúdo, a síntese desses conteúdos e sua transcrição em esquemas e 
imagens, sua organização e configuração diagramática e não-linearidade da leitura (ESCOBAR; SPINILLO, 2016; PAIVA, 2011).

Considerando os conteúdos de genética aplicados ao Ensino Médio, existe uma ideia preestabelecida pelos alunos de que essa é uma matéria de difícil compreensão. Isso se deve ao fato de que o conteúdo de genética emprega constantemente conhecimento de cálculo e raciocínio lógico, além retomar conceitos específicos da Biologia que é de difícil entendimento para os alunos. Por esses motivos que, na maioria das vezes, os alunos deixam essa matéria de lado ou estudam somente o necessário. Logo a união dos infográficos aos conteúdos de genética podem ser mais dinâmicos e menos maçantes, contribuindo para que os alunos tenham um melhor desempenho.

Tendo isso em vista, os objetivos gerais deste trabalho são: confeccionar infográficos que abordem diferentes temas da disciplina de genética e disponibilizá-los ao público alvo: estudantes e professores. Em relação aos objetivos específicos almejamos: elaborar um compilado de infográficos referentes ao conteúdo de genética; criar um canal de divulgação do material produzido; divulgar o uso de infográfico a docentes, visando estimular seu uso.

Apesar de os infográficos serem um recurso de comunicação, eles se reformulam, bem como os demais meios de informação, hoje, já temos os infográficos interativos, que, além de unirem texto verbal e imagens, promovem a participação do leitor. Aliado a isso, temos a inserção da tecnologia nas escolas, o que possibilita o uso de novas ferramentas para o ensino, além do livro didático ou da apostila (SANTOS; CAMPELLO; COUTINHO, 2015).

Por isso, os objetivos previstos podem proporcionar maior conhecimento do infográfico e validar seu uso tanto no contexto didático quanto na divulgação científica. Sendo assim, trataremos, a seguir, da relação entre a infografia e o processo de ensino-aprendizagem. 


\section{OS INFOGRÁFICOS E O ENSINO-APRENDIZAGEM}

Indicativos de diversas avaliações do sistema de ensino nacional revelam uma insuficiência do ensino tradicional das escolas. As causas podem ser atribuída ao fato de que muitos professores ainda não utilizam estratégias que possam otimizar a aprendizagem dos alunos. Na maioria das vezes, o ensino tradicional se limita a transmitir conteúdos aos alunos para que tenham boas notas no final do ano, não valorizando sua aprendizagem real. Contrapondo essa ideia de ensino, temos o processo de ensinoaprendizagem em que o professor integra, realmente, os alunos no processo de "ensinar" (VASCONCELOS; PRAIA; ALMEIDA, 2003).

No processo de ensino-aprendizagem, os alunos devem ser sujeitos ativos e, por isso, os infográficos, no ensino, surgem com o intuito de aproveitar os recursos tecnológicos, estimulara curiosidade dos alunos, contribuindo com seu desenvolvimento do processo de ensinoaprendizagem (CORTES; SILVA; MACIEL; NUNES; SOUZA, 2015 ).

É preciso mudar convicções equivocadas, culturalmente difundidas em toda a sociedade, de que os alunos são os pacientes, de que os agentes são os professores e de que a escola estabelece simplesmente o cenário do processo de ensino (TEODORO; VEIT, 2002, p. 5).

Ao analisar o processo de ensino-aprendizagem dos alunos com relação às disciplinas de Ciências e Biologia, devido a sua reformulação constante, notamos que a linguagem científica, em sua essência, deve ser caracterizada pela linguagem representativa, para facilitar o processo de ensino-aprendizagem dos alunos desta disciplina (TEODORO; VEIT, 2002).

Segundo Dias (2008), no ensino de Ciências e Biologia, as dificuldades de assimulação são causadas por falhas no processo de aprendizagem dos conteúdos. Sendo que seus fracassos podem ser reduzidos quando o professor planejar e permear sua prática pedagógica em dois principais aspectos: primeiro no desenvolvimento de ações que façam ligações entre os alunos e os conteúdos apresentados; seleção de alguns elementos essenciais dos temas apresentados aos alunos, o que é de extrema 
importância para que eles ultrapassem as ideias preestabelecidas (DIAS, 2008).

Dificuldades são recorrentes no processo de aprendizagem da disciplina de Biologia, principalmente em conteúdos que abordam conceitos menos "palpáveis" aos alunos, como, por exemplo, a Citologia, a Genética e a Biologia da Evolução. Ao decorrer do processo, podem surgir conceitos científicos em demasia, que muitas vezes levam os alunos a erros conceituais. Uma alternativa é o desapego ao livro e a busca por novos métodos didáticos que superem as concepções de ensino tradicional, para professores e alunos, como o uso de textos diferenciados para os estudos e na exploração de imagens, gráficos e tabelas, podendo citar como exemplo o uso dos infográficos.

No ensino-aprendizado da disciplina de Biologia, ocorrem dificuldades de ambos os lados, já que pode haver uma incoerência entre professores e alunos durante o processo de adaptação didática. Vale destacar que essa incoerência ocorre que alguns professores utilizam as terminologias, próprias de cada conteúdo, como a Histologia, de modo confuso, não favorecendo à aprendizagem do conteúdo. Por isso, os educadores devem envolver os alunos no processo de aprendizagem, trazendo o cotidiano para dentro da sala de aula, e desenvolver novas metodologias que promovam a compreensão dos alunos com relação aos conceitos fundamentais da disciplina de Biologia.

Por essa razão, é importante acentuar a atuação do professor de Biologia, sendo este o principal incentivador para a construção do pensamento científico dos alunos, para que eles busquem novas informações sobre os avanços científicos (BORTOLUCCl, 2014; HURTADO; GARCÍA, 2003).

\section{A infografia como novo recurso tecnológico-didático}

A partir da década de 1950, surgiram as Tecnologias Educacionais (TE), que permitiram inserir diferentes meios educacionais, como a tecnologia, 
sem questionar suas finalidades. As TE podem ser aplicadas como novos recursos de aprendizagem para os alunos e é um erro pensar que elas são um meio de "passar" o tempo da aula. As Tecnologias Educacionais possibilitam o esclarecimento de equívocos conceituais, além de promover a formação de alunos pesquisadores, devendo serem tratadas como objetivo de ensino, não somente como um meio. Esse tipo de metodologia, ao utilizar-se, da tecnologia ou de outros recursos, é capaz de tornar os alunos mais autônomos e mais ativos; contudo, a metodologia tradicional, ainda muito presente, pode atuar como um reforçador de aprendizagem (CONDE; LIMA; BAY, 2014; LEITE, 2004; OLIVEIRA, 2017).

Graças aos avanços tecnológicos temos o uso de infográficos no processo de ensino-aprendizagem nas escolas, o qual promove uma maior compreensão de grande diversidade de conceitos apresentados. Por possuir uma linguagem diferenciada, os infográficos agem de modo ativo na aprendizagem múltipla representativa dos alunos. Há, ainda, os infográficos multimídias, que mantêm as características essenciais do infográfico, porém agora recorrem a outros processos tecnológicos, o que acrescenta potencialidade, além de estender sua função e incorporar novas ferramentas. São interativos, digitais e/ou animados e podem apresentar seis características do produto informativo, são elas; a multimidialidade, interatividade, hipertextualidade, customização do conteúdo, memória e atualização continua. Assim, o infográfico é uma arte de relação intercambiável com sua apresentação e exploração, isto é, a cognição do conteúdo com o conceito teórico (ALVES, 2014; BOTTENTUIT JUNIOR; LISBOA; COUTINHO, 2011; CLARK; MAYER, 2008; RIBAS, 2004; SCHIMITT, 2006).

O infográfico, no ensino, motiva raciocínio lógico e escrita. Por ser um material de fácil aplicação na sala de aula, ele pode ser criado pelo próprio docente. É um recurso didático que além de ser algo presente na vida dos alunos é um meio de sintetizar e associar diferentes conteúdos. É importante ressaltar que os infográficos podem incluir o aluno em meio de aprendizagem diferenciado (SCAGLIONI; CAMILLO, 2016; JUNIOR; MENDES; SILVA, 2017; MÓDOLO, 2007). 
O uso dos infográficos em sala confere a vantagem do baixo custo, já que pode ser disponibilizado gratuitamente na internet, múltiplos usuários podem consultar uma mesma obra, além de promover a utilização e interação de recursos multimídia no ensino-aprendizagem (LISBÔA; JUNIOR; COUTINHO, 2009).

\section{O benefício da Infografia para a Ciência}

Além dos benefícios educacionais, os infográficos promovem a divulgação científica, pois possibilitam a associação e a interpretação dos conhecimentos científicos do público leigo ao meio científico. Suas diversas características mais marcantes, como a informação verbal e a sua estética, fazem com que os infográficos possuam um alto grau de otimização para a divulgação do saber científico, são mais fáceis de serem lidos e mais atraentes. Sua peculiaridade proporciona a divulgação científica em massa e aproxima os discursos científicos específicos ao público leigo, por isso, são realmente capazes de contribuir com a compreensão dos aspectos mais essenciais da ciência, já que o esclarecimento científico pode ser constituído a partir da associação de imagens, fotografias, ilustrações, tabelas, entre outros. Estudos apontam que a aprendizagem a partir de imagens contribui para a construção, fixação, e apropriação de ideias e fatos dos discursos científicos (ALMEIDA, 2002; ALVAREZ, 2012; CALSAMIGLIA, 1997; COURASOBRINHO; MARTINS, 2013; SOUZA; GIERING, 2010). Nos artigos de divulgação da ciência, a infografia funciona como um recurso a fim de mostrar, explicar e descrever, de maneira rápida e supostamente atraente para o público não especialista, fenômenos científicos de difícil entendimento" (COURASOBRINHO; MARTINS, 2013, p. 6).

A Comunidade Científica é restrita a determinados especialistas de um campo de estudo, e se utiliza de explicações metodológicas, termos e fórmulas particulares, fazendo com que os cientistas sejam vistos pela sociedade, de modo geral, como distantes e elitistas. É fato que, muitos cientistas, mesmo em meio a um público leigo, insistem no emprego da linguagem específica, a qual, muitas vezes, é mal compreendida. A 
Divulgação Científica, propõe-se a popularizar a ciência e o saber científico à comunidade e a democratizar o acesso ao conhecimento científico. É possível verificar canais de mediação responsáveis pela Divulgação Científica, como os jornalistas, fotógrafos e infografistas, encarregados de escrever e ilustrar o saber científico (SATO, 2017).

Os infográficos são capazes de proporcionar discursos científicos menos maçantes e menos complicados, além de serem mais explicativos, oferecendo a aquisição de diversos conhecimentos científicos. O público geral se beneficia com os novos conhecimentos, podendo tornarem-se novos agentes ativos da divulgação do conhecimento científico. Dessa forma, a transmissão do conhecimento científico, mais simplificado, contribui para a participação das pessoas na transformação tecnológica e, em especial, no ensino (CATALDI; GOMES; SOUZA, 2007; HERNANDO, 1997).

\section{O impacto dos infográficos nas salas de aula}

Vem crescendo a utilização dos infográficos em sala de aula como novos meios didáticos, os quais promovem a aprendizagem dos alunos, permitindo que incorporem os conceitos de modo mais concreto. Os infográficos trazem vantagens à metodologia de ensino, como o ganho de tempo, o conhecimento de novos mundos, além do acesso mais produtivo às informações (COUTINHO et al, 2011; MILHEIRO, 2013).

Ademais, o emprego de infográficos é vantajoso a estudantes que apresentam pouco conhecimento prévio sobre diversos conteúdos, como a Física, a Química, a Biologia e outras disciplinas. Ele é utilizado como meio facilitador da compreensão desses conteúdos (COSTA; TAROUCO; BIAZUS, 2011).

É necessário ter em mente as características e potencialidades dos infográficos já que estes apresentam artifícios interativos que, de fato, contribuem para a compreensão dos conteúdos. Sendo assim, os infográficos podem ser utilizados como meios visuais que possibilitem um melhor reconhecimento cognitivo dos conceitos apresentados, pelas imagens, os gráficos, as cores, as formas ou os padrões (SANTOS, 2015). Em 
suas pesquisas, a mesma autora relata que os infográficos foram introduzidos como material educacional na Coleção Vereda Digital, a qual atende alunos do $1^{\circ}, 2^{\circ}$ e $3^{\circ}$ anos do Ensino Médio. Foram aplicados os conteúdos digitais às disciplinas de Biologia, Geografia, Filosofia, Física, Literatura e Sociologia. O material apresentava 237 infográficos digitais e 57 infográficos interativos.

Vale apontar que os resultados das disciplinas de Geografia e Física, que tiveram maior destaque com relação ao uso dos infográficos interativos e digitais, deste modo, os infográficos de Geografia foram identificados como os de preferência dos alunos, pois, promoviam maior compreensão dos conteúdos apresentados caucionado ao emprego preciso de imagens e mapas neste material. Para a disciplina de Física, foram utilizados infográficos de simulação interativa por meio da exploração da interface, os quais promoveram os estímulos aos alunos para solucionar as questões das atividades, como as de Movimento Retilíneo Uniforme (MRU) e as de Movimento Retilíneo Uniformemente Variado (MRUV). Contudo, a pesquisa revelou que alguns alunos preferem que o professor utilize o infográfico como um meio de explicação, não só como material de auxílio para as atividades, pois muitas vezes ocorrem dificuldades na leitura do material. Destaca-se que os alunos tendem a ter uma preferência pelo uso de videoaulas como meio de estudos para as atividades para cessar suas dúvidas no desenvolvimento.

Segundo Calegari e Perfeito (2013), foi realizada uma experiência de leitura com alunos do $1^{\circ}$ ano do Ensino Médio em uma escola particular da cidade de Londrina. A pesquisa tinha como objetivo formar alunos engajados na leitura crítica. Esta atividade foi aplicada no âmbito da Linguagem para que os alunos pudessem aguçar a crítica e possibilitar modificação social. No resultado, foi descrito que os alunos foram receptivos e comparativos nos textos multimodais, ou seja, o gênero textual foi indispensável para o aprendizado dos discentes, tornando-os cidadãos produtores de suas próprias literaturas e escritas, além de expandir sua formação cultural. 
Em uma pesquisa no campo da educação a distância, verificou-se o aproveitamento do uso de infográficos como uma contribuição para aprendizagem. Segundo o pesquisador, os infográficos utilizados foram capazes de desenvolver a capacidade cognitiva e estimular a reflexão dos alunos, isso por oferecer informações diferenciadas com textos e imagens interativas (BRAGA, 2009).

Em um estudo realizado com 54 alunos de graduação, os infográficos foram utilizados como meio de associação de imagens e textos para atingir - apelo visual desejado, favorecer aprendizagem e satisfazer a compreensão dos alunos. O experimento seguiu a metodologia proposta por Wohlin et al (2012) em que primeiramente foi definido o experimento, planejado, executado e por fim analisado. Na fase 1, os alunos deviam responder a um questionário em uma plataforma da web para verificar seus conhecimentos prévios sobre os temas propostos. Na fase 2, os alunos foram distribuídos em três grupos aleatórios em que 18 alunos utilizaram infográficos, 19 alunos utilizaram gráficos e 17 alunos trabalharam com texto, isso para verificar qual material melhor satisfazia a aprendizagem. Na terceira fase, foi aplicado o mesmo questionário dos conhecimentos prévios, nesta fase também foi feito o teste de "Retenção" para analisar, após sete dias, quantos conhecimentos os alunos ainda eram capazes de retomar, isso para verificar e analisar de modo quantitativo qual recurso teve melhor desempenho. Após a execução de todos os testes as análises foram feitas pelo software estatístico R' (LYRA; OLIVEIRA; REIS; CRUZ; NAKAGAWA; ISOTANI, 2016).

O estudo concluiu que o uso dos infográficos como material de aprendizagem favorece a retenção efetiva de conhecimentos, sendo mais apropriado para aprendizagem a longo prazo, pois, os infográficos possuem um design mais atrativo e menos linear, o que favorece maior memorização se comparado aos textos lineares. Foi verificado que os alunos que utilizaram como meio de aprendizado os infográficos tiveram uma média de retenção maior do que os alunos que utilizaram recurso textual, sendo assim a média 
de retenção, dos infográficos foi de 16,13 e a média de retenção dos recursos verbais de 13.

Em uma pesquisa realizada com alunos do $9^{\circ}$ ano do Ensino Fundamental, os alunos produziram um infográfico, utilizando o programa Piktochart, voltado para o ensino de Química e Física. Eles foram separados em grupos, nos quais teriam que escolher os conceitos de Química e Física que pretendiam trabalhar. Foi evidenciado que, com a montagem dos infográficos, os alunos puderam expressar seus conhecimentos e relacionálos com situações de seu cotidiano, utilizando a criatividade, autonomia, o pensamento crítico e suas habilidades com tecnologias digitais. Por fim, os alunos imprimiram e apresentaram seus trabalhos aos colegas de classe de modo que todos eles pudessem se ambientar com os conceitos ali apresentados (BULEGON; DRESCHER; SANTOS, 2017).

\section{METODOLOGIA}

Este trabalho foi realizado com base em pesquisa bibliográfica de acordo com o proposto por Gil (2008, p. 28), isto é, os livros e artigos científicos foram os materiais base para o desenvolvimento do traballho. Isso com o intuito de averiguar como os infográficos podem ser aplicados no ensino-aprendizagem de jovens-adolescentes, e quais são os conteúdos de genética presentes no Ensino-Médio que podem ser contemplados em tal metodologia.

Os infográficos serão produzidos no programa online Piktochart (figura 1), que apresenta duas versões, a gratuita e a paga. Além disso, no programa é possível produzir relatórios com frequência e apresentações (figura 2). Iremos utilizar a versão gratuita, na qual há a oferta de alguns templates (modelos) e um editor fácil de usar, mas a versão paga disponibiliza centenas de templates, e para ambas as versões ainda não possuem um app (aplicativo). Sua versão gratuita é compatível a qualquer navegador, porém, só se encontra acessível em inglês. Para operar na 
versão gratuita do Piktochart é preciso fazer um cadastro, com email e senha.

Figura 1: Piktochart.Print da tela inicial do programa Piktochart

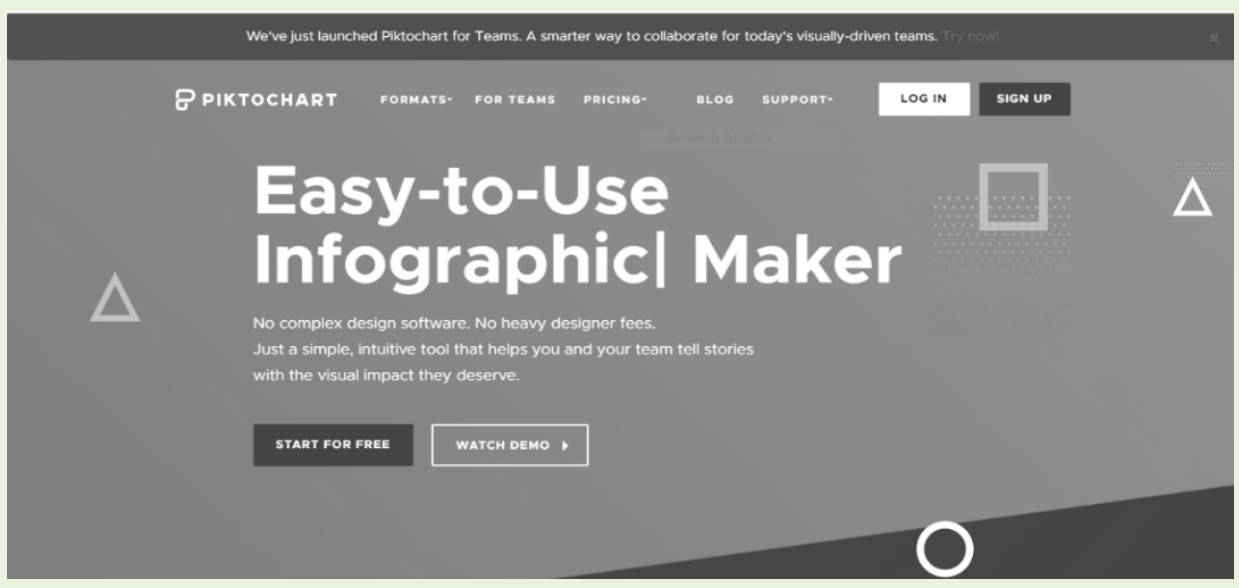

Fonte: Autor.

Os números 1, 2, 3 mostram a captura da tela para escolha de um infográfico, uma apresentação e um relatório com frequência respectivamente.

Figura 2: Dispositivos do Piktochart. Captura da tela dos dispositivos do programa Piktochart

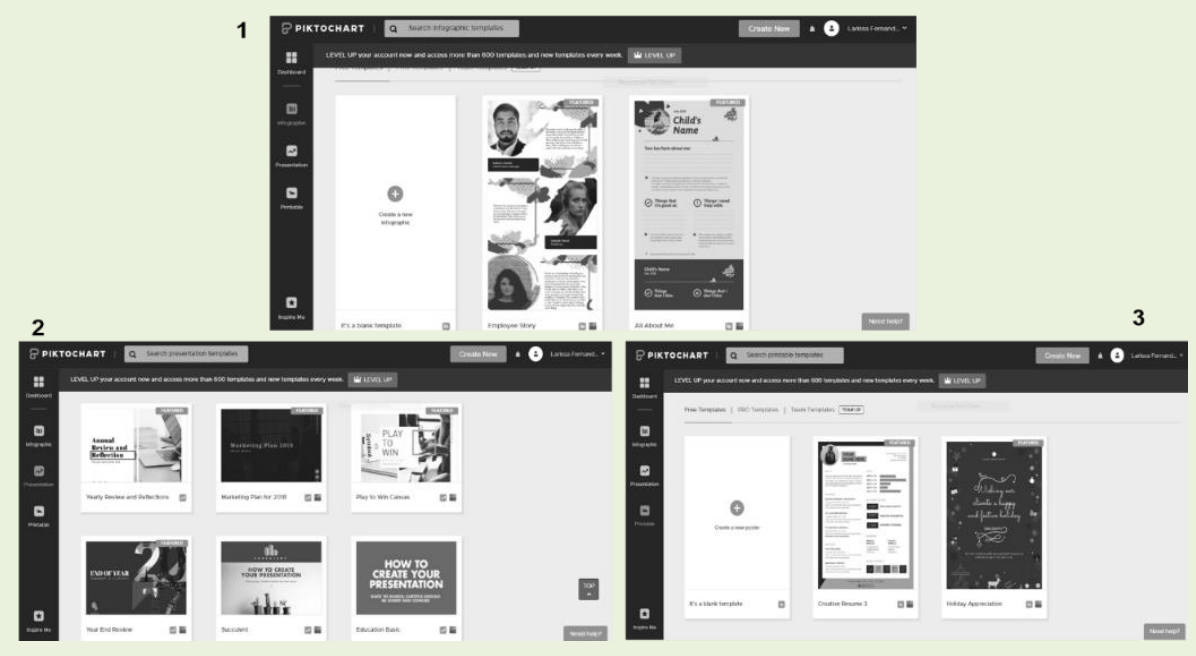

Fonte: Autor.

Logo após o registro, o usuário tem acesso aos diferentes dispositivos, infográficos, relatórios com frequência e apresentações.-Ao selecionar um deles, tem-se o acesso a uma página que dispõe de interfaces localizadas 
em uma coluna da esquerda da tela, a qual possui variados itens como seleção de ícones, formas, fotos e quadro de fotos, opção de realizar o download de imagens, gifs e vídeos, escolha de diferentes fundos, além de ferramentas para construção e formatação de mapas, gráficos e vídeos (figura 3). Ribeiro, Medeiros e Goulart (2017), a criação dos infográficos deve ser pautada com cuidado em relação à escolha dos temas, cores, imagens, texto, dados e desenhos.

Figura 3: Ferramentas para os Infográficos

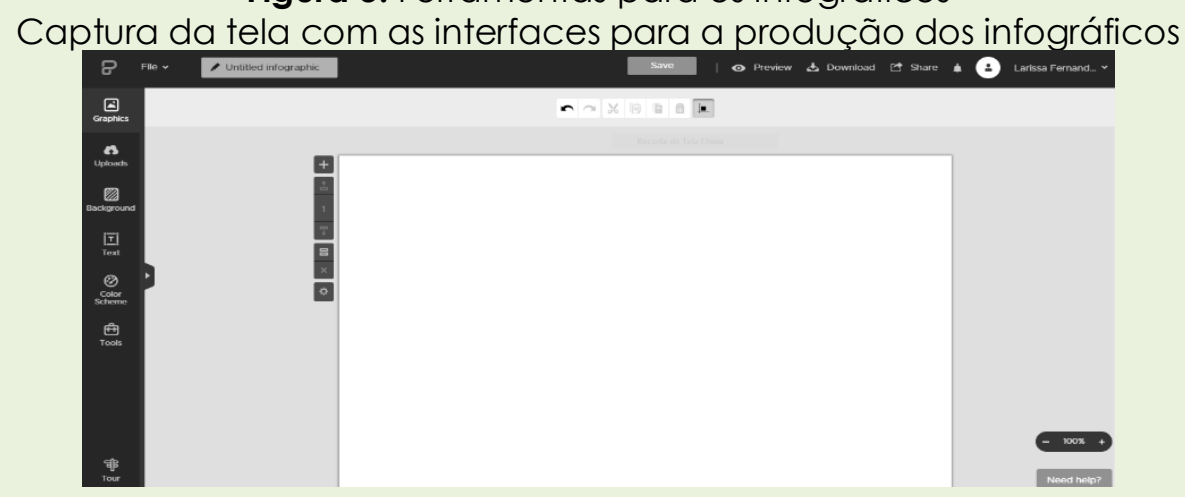

Fonte: Autor.

Diante disso, serão produzidos três infográficos com alguns conteúdos que compõem o assunto de genética no Ensino Médio. Esses conteúdos são: padrões de herança, as autossômicas e ligadas ao sexo; cariogamia humana e interação gênica como epistasia. Os infográficos serão ordenados com relação ao nível de dificuldade, isto é, do mais fácil ao mais difícil. O infográfico sobre padrões de herança apresente menor complexidade; por essa razão esse será de fácil compreensão, se comparado ao infográfico sobre espistasia.

A divulgação do material terá como alvo o ensino-aprendizado alternativo, por isso, optamos pala criação de uma página do Facebook (figura 4), que é um dos websites mais papulares da Internet, suas páginas de acesso possibilitam atingir público (alunos e professores) mais específico, facilita múltiplas visualizações, não tem custo e como pode ser acessado pelo aparelho celular permite que os infográficos sejam acessados de modo mais fácil e rápido. A página do Facebook que foi criada possui o nome Bio+ Ativa, Bio+ para designar ao ensino de Biologia, mesmo porque partimos do 
princípio de que outros conteúdos de Biologia serão produzidos futuramente e também poderão ser publicados na página. A palavra Ativa, caracteriza as Metodologias Ativas que se baseiam em formas de desenvolver 0 processo de aprendizagem através de metodologias que têm o potencial de despertar a curiosidade nos alunos (BERBEL, 2011).

Figura 4: Página Bio+ Ativa. Captura da tela da página de divulgação do Facebook

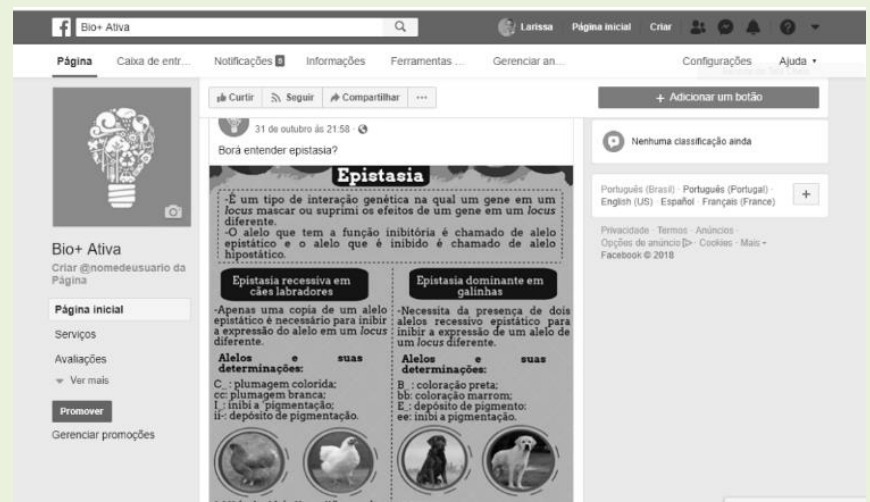

Fonte: Autor.

Para a divulgação física (impressos) dos infográficos dentro do Instituto Federal do Paraná (IFPR) Campus Londrina, serão oferecidos para os professores, tanto os infográficos voltados aos conteúdos de genética quanto os outros conteúdos de biologia. Visando atender o público alvo, os alunos vestibulandos e alunos da graduação, os infográficos serão dispostos nos corredores do interior do prédio para visualização. Por fim serão disponibilizados outros infográficos com diversos conteúdos de biologia para melhoria da preparação dos alunos.

\section{RESULTADOS}

Até o presente momento, concluímos a confecção de três infográficos completos, seguindo parâmetros, sugestões e ideias apresentadas na revisão bibliográfica e por meio do uso de softwares, como os descritos na metodologia do presente trabalho. 
Cada infográfico representa um modelo/estilo diferente do outro e que será replicado na confecção dos demais infográficos até a conclusão do projeto de acordo com as peculiaridades de cada tema.

$\mathrm{Na}$ visão dos autores deste artigo o infográfico com o tema Padrões de Herança (figura 5) é um conceitual com as informações dispostas na forma de tópicos destacando uma explicação breve do conceito, bem como um exemplo de aplicação deste no cotidiano.

Figura 5: Padrões de Herança, Explicação sucinta sobre Padrões de herança, em que o conteúdo é apresentado em tópicos

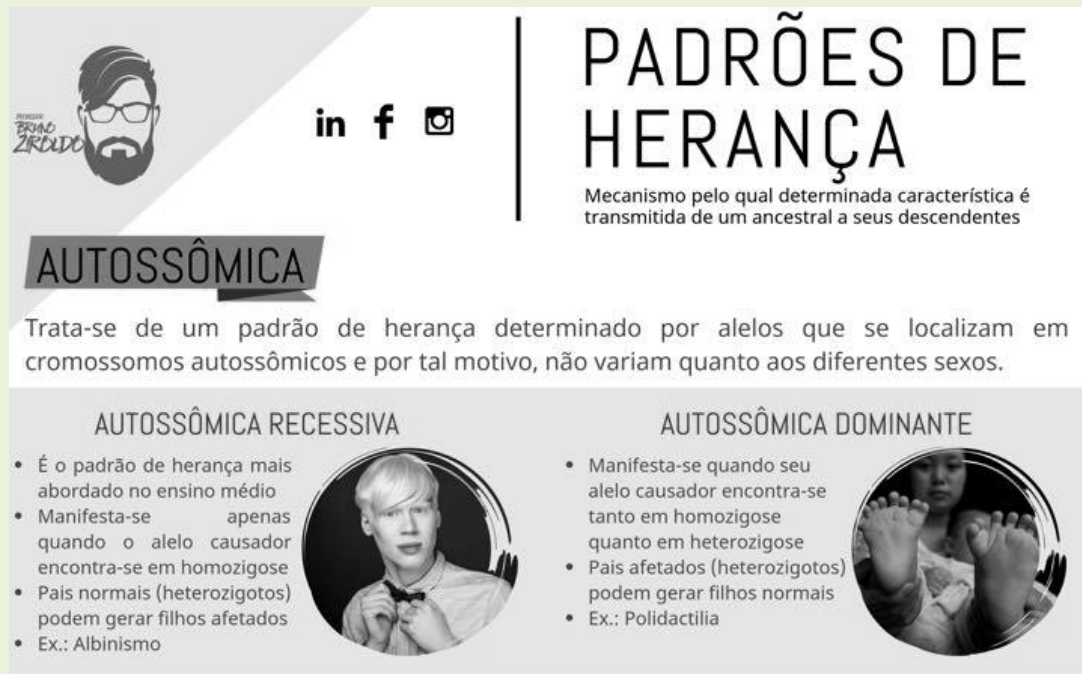

\section{LIGADA AO SEXO}

Trata-se de um padrão de herança determinado por alelos que se localizam nos cromossomos sexuais ( $\mathrm{X}$ e $\mathrm{Y}$ ) e por tal motivo, variam quanto aos diferentes sexos.

\section{LIGADA AO CROMOSSOMO $X$}

- Manifesta-se quando o alelo causador situa-se na região do cromossomo $X$ que não apresenta homologia com $Y$

RECESSIVA

- No homem, a anomalia manifesta-se em qualquer portador de um único alelo. Na

mulher, apenas quando o alelo está em homozigose.

- O homem afetado passa o alelo a todas suas filhas

- O homem afetado herdou o alelo de sua mãe

- Apresenta salto de gerações afetadas no heredograma

- Ex.: Daltonismo, hemofilia e distrofia muscular de Duchenne

DOMINANTE

- Tanto no homem quanto na mulher a anomalia manifesta-se na presença de um único alelo

- Não apresenta salto de geraçōes afetadas no heredograma

- Ex.: Raquitismo hipofosfatêmico e Síndrome de Rett

\section{LIGADA AO CROMOSSOMO Y}

- Manifesta-se quando o alelo causador situa-se na região do cromossomo $Y$ que năo apresenta homologia com X

- Por conta do referido cromossomo ser exclusivo do sexo masculino, tal herança

comumente é chamada de holândrica (holos = todo; andros = masculino) ou restrita

ao sexo

- Ex.: Formação dos testículos

Fonte: Autor. 
Tal modelo dispõe de poucas imagens em detrimento de informações diretas e sem a necessidade de uso de esquemas, gráficos e/ou outros recursos. Acreditamos que essa ideia de infográfico seja eficiente para ilustrar temas mais conceituais como por exemplo, as premissas abordadas nas Leis Mendelianas ou até mesmo outros conceitos básicos de genética.

O infográfico sobre Cariótipo Humano (Figura 6) já se manifesta menos denso do ponto de vista conceitual que o anterior, perfazendo sua estrutura focado na apresentação e na tradução de símbolos/fórmulas cariótipos, ideia que pode ser replicada com sucesso em outros temas como Mutações e Genética Populacional, por exemplo.

Figura 6: Cariótipo Humano

Apresentação e tradução de símbolos do disposto em esquema

\section{GARIÓTIPQ

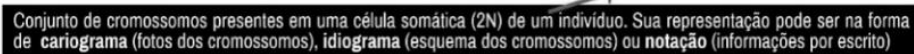

NOTACÃO PADRÃO : Uma notaçăo padrão de cariótipo é composta de ao menos dois termos, sendo que a

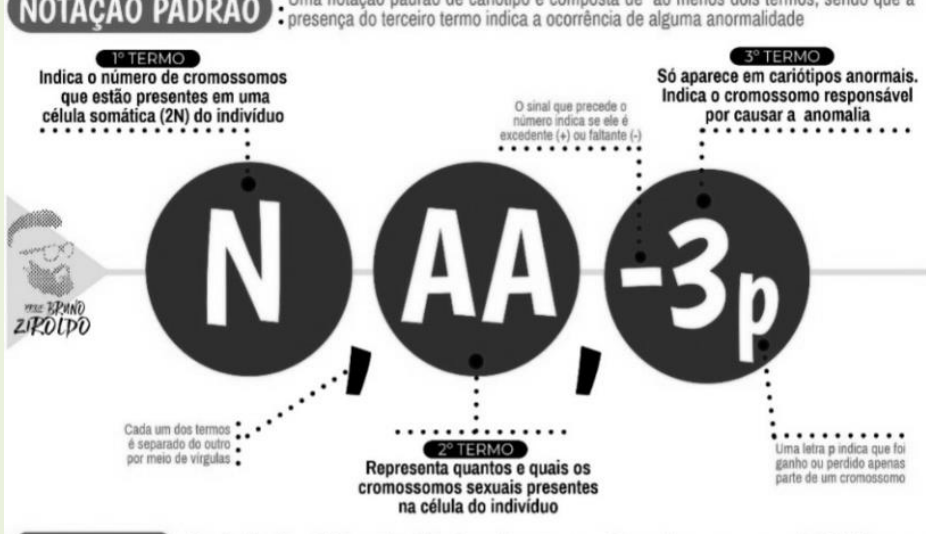

EXEMPLOS : A notacaão do cariótipo pode não só revelar o sexo e número de cromossomos do individuo, más
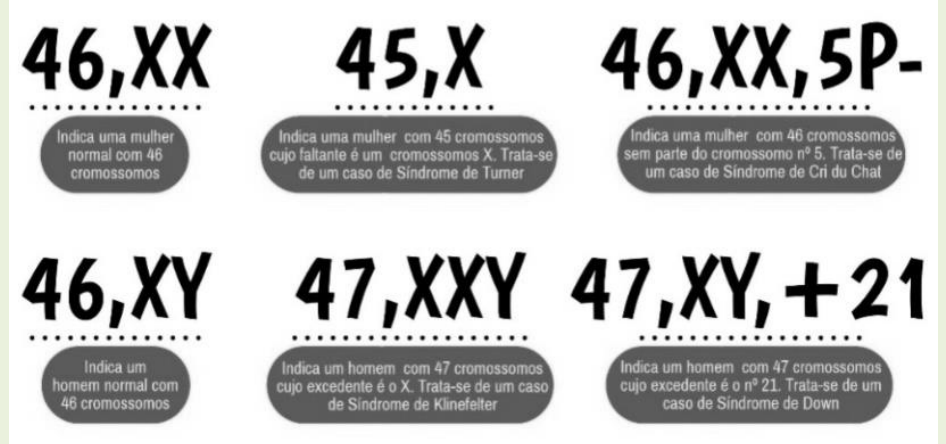

Fonte: Autor. 
Por fim, o terceiro infográfico, confeccionado com o tema Epistasia (figura 7), trabalha com conceitos prévios, exemplificação, tradução de linguagem específica (genótipos), imagens e esquematização, traduzindo-se em um modelo mais completo, que pode ser empregado com sucesso na explicação de temáticas como Ligação Gênica e Herança Quantitativa, por exemplo.

Figura 7: Epistasia conceitos prévios e esquema de modo mais completo

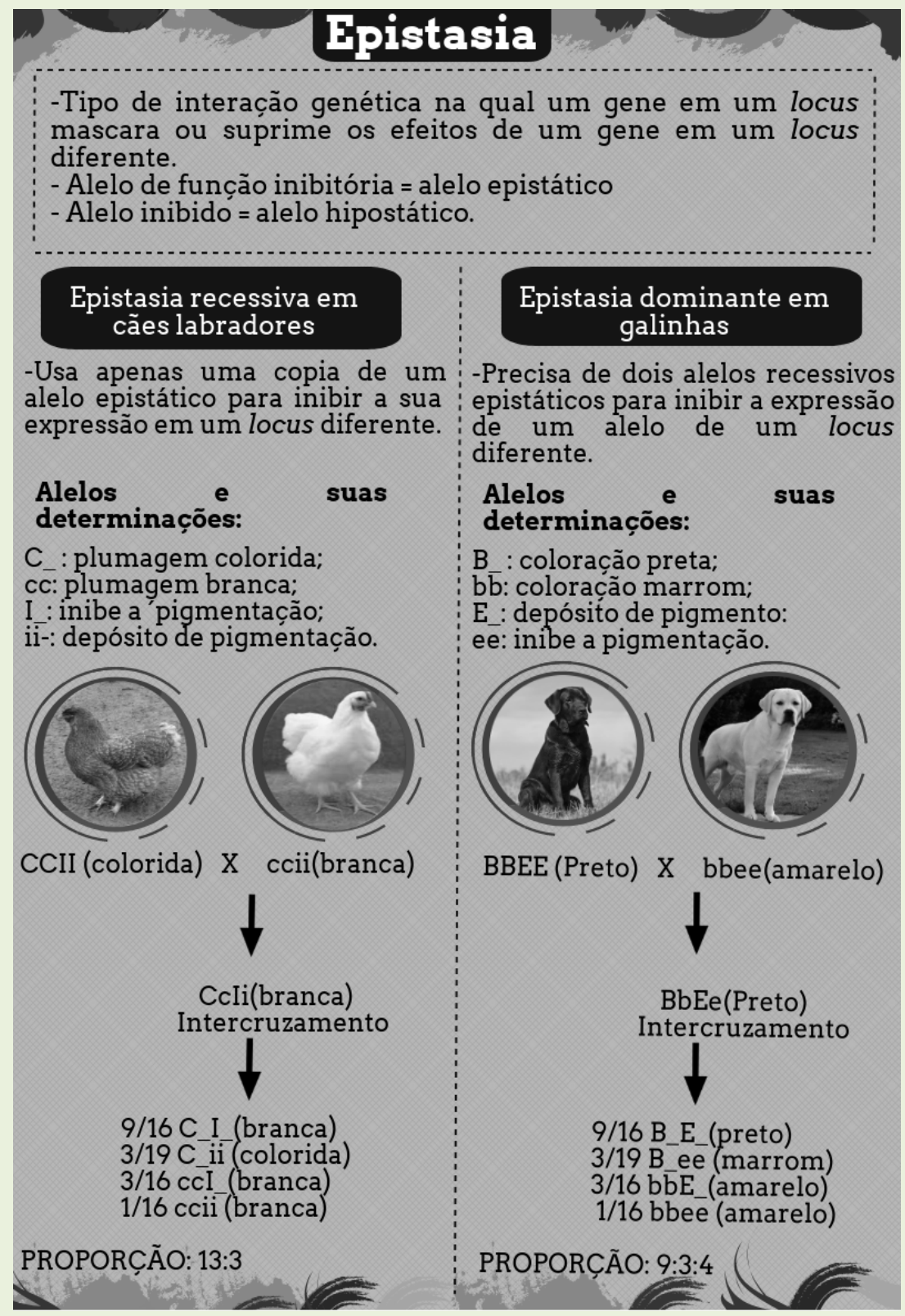

Fonte: Autor. 
Os três infográficos foram divulgados em redes sociais dos autores bem como na página criada com esse fim específico na rede social Facebook, chamada Bio+ Ativa.

Além da divulgação online, os infográficos foram disponibilizados aos docentes que se interessaram em aplicar o recurso em suas aulas, bem como para alunos no incremento do seu aprendizado/estudo.

Ao final do projeto, todos os infográficos relacionados à Genética irão compor um compilado com versões física e digital, sendo previamente enviados à Biblioteca Nacional para fins de registro de direitos autorais sobre a obra, assim como já realizado com outros infográficos de projetos paralelos a este.

Ao dispor os conceitos apresentados nos infográficos de modo mais sintetizado, foi necessário aprofundar os conteúdos, retomando além dos conceitos principais, conceitos auxiliares, por exemplo, é impossível ensinar genética sem conhecer a bioquímica ou citologia - mas também para que o infográfico não seja uma mera replicação do que se observa no livro didático e sim um apoio efetivo, complementar, significativo e de apelo visual, o que invariavelmente leva o docente a se reinventar do ponto de vista estético e organizacional.

Por fim, é inegável que a produção do infográfico eleva a qualidade do material de apoio utilizado pelo docente pois, por ser resultado de seu trabalho, é personalizado e atende aos seus anseios e necessidades de um modo particular que qualquer outro material pronto não teria essa capacidade, pois seu infográfico foi idealizado e construído para esse fim. A habilidade do educador em produzir o próprio material o liberta da dependência de buscar e adaptar materiais prontos sem a garantia de conseguir aplicá-lo em sua aula ou ainda da necessidade de adaptar sua aula em torno do material que dispõe.

\section{CONCLUSÃO}

É importante apontar que os alunos de hoje utilizam, cada vez mais, ferramentas para aumentar seus conhecimentos, sendo assim, são cada vez 
mais autônomos; por isso, os professores têm potencial de utilizar novas metodologias educacionais que impulsionem e estimulem o processo de ensino-aprendizagem dos seus alunos. Nesse sentido, a infografia é um recurso inovador para novas práticas de ensino-aprendizagem promovendo, deste modo, a atenção do aluno.

As infografias têm como característica a junção de informações teóricas com imagens, promovendo uma abordagem mais dinâmica dentro de sala de aula e possibilitando que os alunos exercitem o pensamento crítico e reflexivo. Além do aprendizado, os infográficos propiciam um maior grau de entusiasmo por parte dos alunos, ao contrário dos textos narrativos ou explicativos. Quando utilizados pelos professores como recurso auxiliar no ensino de conteúdos específicos, os infográficos tornam-se um forte aliado, eles viabilizam a exposição de grande quantidade de dados, além explicitar ideias e conceitos por meio de códigos visuais de modo mais claro e com maior detalhamento.

A evolução das tecnologias possibilitou o aprimoramento dos infográficos, que podem explorar aspectos específicos e singulares de determinado assunto. É um recurso didático revolucionário que possibilita, ao aluno, visualizar a informação e os dados ali apresentados, dando sentido ao assunto de uma forma aprofundada.

A combinação verbal e visual, dos infográficos promove a divulgação científica com um efeito interpretativo e reflexivo, pois, as imagens facilitam a retenção de informações, favorecem o saber científico e cumprem o papel de atender às demandas sociais de informação. Os infográficos, também, oferecem a transmissão de informações de modo mais dinâmico e de fácil processamento.

Assim retomamos nossos objetivos gerais que foram confeccionar infográficos que abordem diferentes temas da disciplina de genética e disponibilizá-los ao público alvo: estudantes e professores. E os objetivos específicos elaborar um compilado de infográficos referentes ao conteúdo de genética; criar um canal de divulgação do material produzido; divulgar o uso de infográfico a docentes, visando estimular seu uso. 
Por fim foi produzido, até o momento, um total de três infográficos com tema de genética e disponibilizados, para professores e estudantes, na página do Facebook Bio + Ativa e no bloco do IFPR Campus Londrina

Com tudo isso fica claro que há a necessidade de estimular novos trabalhos que tratem do uso de infográficos relacionados ao processo de ensino-aprendizagem e, em especial, a divulgação científica.

\section{REFERÊNCIAS}

ALMEIDA, M. O. A vulgarização do saber. Ciência e público: Caminhos da divulgação científica no Brasil, p. 65-72, 2002. Disponível em: <http://www.redpop.org/wp-content/uploads/2015/06/Ci\%C3\%AAncia-eP\%C3\%BAblico-caminhos-da-divulga\%C3\%A7\%C3\%A3o-cient\%C3\%ADficano-Brasil.pdf>.

ALVAREZ, A. M. T. et al. Infografia na educação: contribuições para o pensar crítico e criativo. 2012. Tese de Doutorado. Pontifícia Universidade Católica de São Paulo, Brazil. 2012.

ALVES, A. El arte funcional: infografía e visualización de información. Temática, v. 9, n. 12. 2014. Disponível em: <http://periodicos.ufpb.br/index.php/tematica/article/viewFile/21337/11783>

BERBEL, N. A. N. As metodologias ativas e a promoção da autonomia de estudantes. Semina: Ciências Sociais e Humanas, v. 32, n. 1, p. 25-40, 2011.

BORTOLUCCI, G. G. M. Análise da aprendizagem de biologia no ensino médio através das metodologias da educação ambiental. 2014.

BOTTENTUIT JUNIOR, J. B.; LISBOA, E. S.; COUTINHO, C. P. O infográfico e as suas potencialidades educacionais. 2011.

BRAGA, C.S. O Infográfico na Educação a Distância: uma contribuição para a aprendizagem. In: $15^{\circ}$ Congresso Internacional ABED de Educação a Distância. 2009. p. 27-30.

BULEGON, A.; DRESCHER, C.; DOS SANTOS, L. R. Infográficos: possibilidade de atividades de ensino para aulas de Física e Química.

CAIRO, A. Infografia 2.0: visualización-interactiva de información. Madrid: Alamut, 2008. 
CALEGARI, D. A.; PERFEITO, A. M. Infográfico: possibilidades metodológicas em salas de aula de Ensino Médio. Entretextos, v. 13, n. 1, 2013.

CALSAMIGLIA, H. Divulgar: itinerarios discursivos del saber: Una necesidad, un problema, unhecho. Quark, p. 9-18, 1997.

CARVALHO, J.; ARAGÃO, I. Infografia: conceito e prática. InfoDesign-Revista Brasileira de Design da Informação, v. 9, n. 3, p. 160-177, 2012.

CATALDI, C.; GOMES M. C. A.; DE SOUZA MELO, M. S. Gênero discursivo, mídia e identidade. Editora UFV, Universidade Federal de Viçosa, 2007.

CLARK, R. C.; MAYER, R. E. E-Learning e a Ciência da Instrução: Diretrizes Comprovadas para Consumidores e Designers de Aprendizagem Multimídia, $2^{a}$ ed. (San Francisco: Pfeiffer/John Wiley\& Sons). 2008.

COLLE, R. Infografía: tipologías. Revista latina de comunicación social, v. 7, n. 58, p. 1, 2004.

CONDE, T. T.; DE LIMA, M. M.; BAY, M. Utilização de metodologias alternativas na formação dos professores de biologia no ifro-campus ariquemes. Revista Labirinto (UNIR), v. 18, p. 139-147, 2014.

CORTES, T. P. B. B. et al. A infografia multimídia como recurso facilitador no ensino-aprendizagem em sala de aula. InterSciencePlace, v. 1, n. 29, 2015.

COSTA, V. M.; TAROUCO, L. M. R. Infográfico: características, autoria e uso educacional. RENOTE-Revista Novas Tecnologias na Educação, v. 8, n. 3, 2010.

COSTA, V. M.; TAROUCO, L. M. R.; BIAZUS, M. C. V. Criação de Objetos de Aprendizagem baseados em infográficos. recuperado el, v. 29, 2011.

COURA-SOBRINHO, J.; MARTINS, S. A Infografia Como Mescla Das Matrizes Verbais e Visuais Em Textos De Divulgação Científica: Da Cultura Da Linha À Cultura Da Superfície. Revista Práticas de Linguagem, v. 3, n. 2, 2013.

DIAS, M. A. S. Dificuldades na aprendizagem dos conteúdos de Biologia e as concepções alternativas: constatações a partir do índice de aproveitamento nas provas de múltipla escolha dos Vestibulares da UFRN, no período entre 2001 e 2008. Doutorado em Educação), Universidade Federal do Rio Grande do Norte, Natal, 2008.

ESCOBAR', B. T.; SPINILLO, C. G. Infografia e educação: Proposta de processo de design para infográficos na educação à distância. Blucher Design Proceedings, v. 2, n. 9, p. 1158-1170, 2016. 
GIL, A. C. et al. Como elaborar projetos de pesquisa. São Paulo: Atlas, 2002.

HERNANDO, M. C. La difusióndelconocimiento al publico: cuestiones y perspectivas. Comunicação \& Sociedade, n. 29, 1998.

HURTADO, M. T.; GARCÍA, F. G. Algunas dificultades em la-enseñanza de la histología animal. Revista Electrónica de Enseñanza de lasCiencias, v. 2, n. 2 , p. 177-200, 2003.

JUNIOR, J. B. B.; MENDES, A. G. L. M.; DA SILVA, N. M. O Uso do Infográfico em Sala de Aula: Uma Experiência na Disciplina de Literatura. Revista Educaonline, v. 11, n. 3, p. 105-127, 2017.

LEITE, L. S. (Coord.). Tecnologia educacional: descubra suas possibilidades na sala de aula. Colaboração de Cláudia Lopes Pocho, Márcia de Medeiros Aguiar, Marisa Narcizo Sampaio. 2ºd. Petrópolis-RJ: Vozes. 2004.

LISBÔA, E. S.; BOTTENTUIT JUNIOR, J. B.; COUTINHO, C. P. O contributo do vídeo na educação online. 2009.

LYRA, K. T. et al. Infográficos versus materiais de aprendizagem tradicionais: uma investigação empírica. RENOTE-Revista Novas Tecnologias na Educação, v. 14, n. 2, 2016.

MILHEIRO, S. C. S. G. A infografia como recurso didático. 2013.

MÓDOLO, C. M. Infográficos: características, conceitos e princípios básicos. In: Congresso Brasileiro de Ciências da Comunicação da Região Sudeste. 2007. p. 1-15.

OLIVEIRA, M. R. N. S. Tecnologias Interativas e Educacionais. Revista Educação em Debate, v. 21, n. 37, 2017, p. 150-156.

PAIVA, F. A. O gênero textual infográfico: leitura de um gênero textual multimodal por alunos da $1^{a}$ série do ensino médio. Revista @@ el em (dis-) curso. ISSN 2175-4640, v. 3, n. 1, p. 87-101, 2011.

RANIERI, P. R. A infografia digital animada como recurso para transmissão da informação em sites de notícia. Prisma. com, n. 7, p. 260-274, 2008.

RIBAS, B. Infografia Multimídia: um modelo narrativo para o webjornalismo. Anais do II SBPJor (CD-ROM). Salvador-BA/Brasil, 2004.

RIBEIRO, W. C. P.; DE MEDEIROS, P. R.; GOULART, R. F. USO DE INFOGRÁFICOS COMO MECANISMO DE MELHORAMENTO DO APRENDIZADO. Anais do Seminário de Pesquisa e Inovação Tecnológica-SEPIT, v. 1, n. 1, 2017. 
SANTOS, G. M. S. Infográficos interativos como material escolar: um estudo sobre a utilização de infográficos digitais interativos para compreensão de conteúdo escolar no ensino médio. 2015. Dissertação de Mestrado. Universidade Federal de Pernambuco.

SCAGLIONI, C. M. C. Infográficos e Livros Digitais como Recursos no Contexto Escolar. Revista EaD\& Tecnologias Digitais na Educação, vol. 5, 2017. SCHMITT, V. et al. A infografia jornalística na ciência e tecnologia: um experimento com estudantes de jornalismo da Universidade Federal de Santa Catarina. 2006.

SOUZA, J. A. C.; GIERING, M. E. O infográfico: a palavra e a imagem em texto da divulgação científica midiática. Revista Linguagem \& Ensino, v. 13, n. 2, p. 295-317, 2010.

TEODORO, V. D.; VEIT, E. A. Modelagem no ensino: aprendizagem de física e os novos parâmetros curriculares nacionais para o ensino médio. Revista brasileira de ensino de física, v. 24, n. 2, p. 87-96, 2002.

VASCONCELOS, C.; PRAIA, J. F.; ALMEIDA, L. S. Teorias de aprendizagem e o ensino/aprendizagem das ciências: da instrução à aprendizagem. Psicologia escolar e educacional, v. 7, n. 1, p. 11-19, 2003.

Recebido em: 09 de setembro de 2020 Aprovado em: 02 de novembro de 2020 Publicado em: 16 de dezembro de 2020 